\title{
The association of hospital emergency admissions due to respiratory-cardiovascular diseases and acute myocardial infarction with air pollution in Tehran during 2005-2014
}

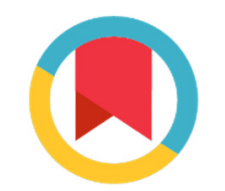

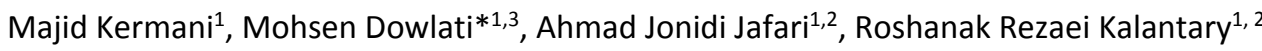 \\ Received: 2 July 2017 \\ Published: 26 Aug 2018
}

\begin{abstract}
Background: Air pollution is one of the main reasons for disease and emergency hospitalizations. Therefore, air pollution control and hospital preparedness are of paramount importance. This study was conducted to determine the association of air pollutant levels with the rate of hospital emergency admissions due to respiratory and cardiovascular diseases and acute myocardial infarction in Tehran during the last decade.

Methods: This was a cross sectional study. At first, information on hourly concentration of air pollutants was gathered from Tehran Environmental Protection Agency and Air Quality Control Company. Raw data and meteorological parameters were used in Excel format to prepare an input file. The number of emergency hospital admissions due to pollutant exposure was assessed using the AirQ2.2.3 model.

Results: Results of this study revealed that there were 54352 cases of emergency hospitalizations due to respiratory diseases in a relative risk of 1.0048 [1.0008-1.0112] and 20990 cases of emergency hospitalizations due to cardiovascular diseases in a relative risk of 1.009[1.006-1.013] during 2005-2014. In addition, 3478 patients were admitted to the emergency department because of acute myocardial infarction with RR of 1.0026 [1.0026-1.0101].

Conclusion: This study demonstrated that a high percentage of hospital emergency admissions was because of respiratory and cardiovascular diseases. Moreover, it was found that acute myocardial infarction could be due to the high level of air pollution and could increase admissions to the emergency department. Therefore, appropriate measures are needed to reduce air pollution and increase hospital preparedness.
\end{abstract}

Keywords: Air pollution, Emergency, Respiratory diseases, Cardiovascular diseases

Copyright $₫$ Iran University of Medical Sciences

Cite this article as: Kermani M, Dowlati M, Jonidi Jafari A, Rezaei Kalantary R. The association of hospital emergency admissions due to respiratory-cardiovascular diseases and acute myocardial infarction with air pollution in Tehran during 2005-2014. Med J Islam Repub Iran. $2018(26$ Aug);32:76. https://doi.org/10.14196/mjiri.32.76

\section{Introduction}

Air pollution has an environmental effect on health (1). WHO reports that in 2012 around 7 million people died of air pollution exposure, 1 out of 8 in total global deaths (2). Numerous epidemiological studies in Iran (3-7), Europe, and other parts of the world (8-10) have shown a relationship between the effects of air pollution and human health. Some epidemiological studies have found a relationship

Corresponding author: Mohsen Dowlati, mohsendowlati.69@gmail.com

1. Research Center for Environmental Health Technology, Iran University of Medical Sciences, Tehran, Iran.

2. Environmental Health Engineering Department, School of Public Health, Iran University of Medical Sciences, Tehran, Iran.

3. Health in Disasters and Emergencies Department, School of Health Management and Information Sciences, Iran University of Medical Sciences, Tehran, Iran. between air pollution and hospital admissions due to cardiovascular diseases (HACVD) (11-17). The results of these studies confirmed the direct relationship of air pollution and rate of admission with respiratory and cardiovascular diseases. Considering Tehran's population of over 10 million, its location, topography, and particular weather area, this city is one of the most contaminated cities in

$\uparrow$ What is "already known" in this topic:

Air pollution in Tehran, especially in the recent decade, has imposed serious problems on the society's health and environment. In Tehran, the average of annual concentration of pollutants is more than the standard level, and air pollution causes mortality and cardiovascular and respiratory diseases in residents of Tehran.

$\rightarrow$ What this article adds:

No assessment has been done about the consequences of air pollution on the health of residents of Tehran during the last decade. This study used the WHO approach and AirQ software. Air pollution impacts health, and thus its assessment is highly important to help authorities and policy-makers. 
the world $(18,19)$. Air pollutants cause such respiratory diseases as asthma, bronchitis, and emphysema. Also, air pollutants can increase cardiovascular diseases, raise the number of cases of hospitalization, and lead to early mortality. Sang Jin Jeong. in a study titled, "Impact of air pollution on human health in Suwon " indicated that the particulate matter had the most health effects on 1118000 people of Suwon, causing 105 to 4254 mortalities in a year (10). Another research performed by Younusian et al. in Tehran entitled, "The relationship between exposure to air pollution and the onset of acute coronary attacks syndrome" showed a main correlation between acute coronary syndrome and median daily carbon monoxide as per the rise of each unit of CO concentration (20). The challenge of air pollution has attracted the attention of governmental and academic authorities in the recent years. Tehran is the most populated city in Iran and its rate of air pollution is rising. Thus, it is expected that a large number of patients visit the emergency department of hospitals because of air pollution. Thus, this study was conducted to determine the impact of air pollution on the rate of emergency hospitalization due to cardiovascular and respiratory diseases in Tehran during 2005-2014.

\section{Methods}

\section{Characteristics of the location}

This cross sectional and descriptive study was conducted in Tehran, the capital of Iran. Tehran is categorized as one of the most polluted cities in Western Asia and 19th in the world. Generally, $20 \%$ of the total energy of the country is used in Tehran. This city is located at $35^{\circ} 41^{\prime} \mathrm{N}$ $51^{\circ} 25^{\prime} \mathrm{E}$, it is $1000-1800$ meters above the see level, and it is restricted on the north, northwest, east, and southeast by high (1000-3800-m) mountains (Fig. 1). The mountain range prevents the humid winds from reaching Tehran and it does not allow the contaminated air to leave the city.
Therefore, during the winter, lack of the wind current and cold air causes the polluted air to be trapped within the city (23). The mentioned factors have caused Tehran to be one of the worst regions in the world for air pollution.

\section{Environmental monitoring data and exposure assess- ment}

Hourly monitoring of air pollutants was performed by the Department of Environmental (DOE) and Tehran Air Quality Control Company (TAQCC) at weather stations around the city (Fig. 1). Hourly data related to air pollutants were collected at monitoring stations. The following numbers in parentheses demonstrate the number of monitoring stations in every year: 2005 (11), 2006 (14), 2007 (14), 2008 (15), 2009 (18), 2010 (37), 2011(36), 2012 (35), 2013 (35), and 2014 (33). Validation of data to conduct statistical analysis was done based on WHO index. Also, the following numbers in parentheses demonstrate the number of valid stations in every year: 2005 (10), 2006 (10), 2007 (11), 2008 (11), 2009 (11), 2010 (19), 2011(15), 2012 (33), 2013 (11), and 2014 (29).

To assess data validity based on WHO standards to perform statistical analysis, the data registered at stations have to be filtered. In the primary filtering to eliminate invalid data, the ratio of valid data of warm seasons to the cold seasons should not be more than 2 . Furthermore, to estimate the daily average, at least $50 \%$ of data should have adequate validity (21).

Daily data on average temperature and average humidity were prepared by Iran Meteorological Organization. In the next step, statistical indicators, including annual mean, warm season mean, cold season average, annual 98 percentiles, the annual maximum, and the maximum content for warm and cold seasons of the air pollutants, were calculated in Excel. The population presented by Iran Statistics Center (ISC) was considered as the population at risk of exposure to air pollution. In the AirQ software, estima-

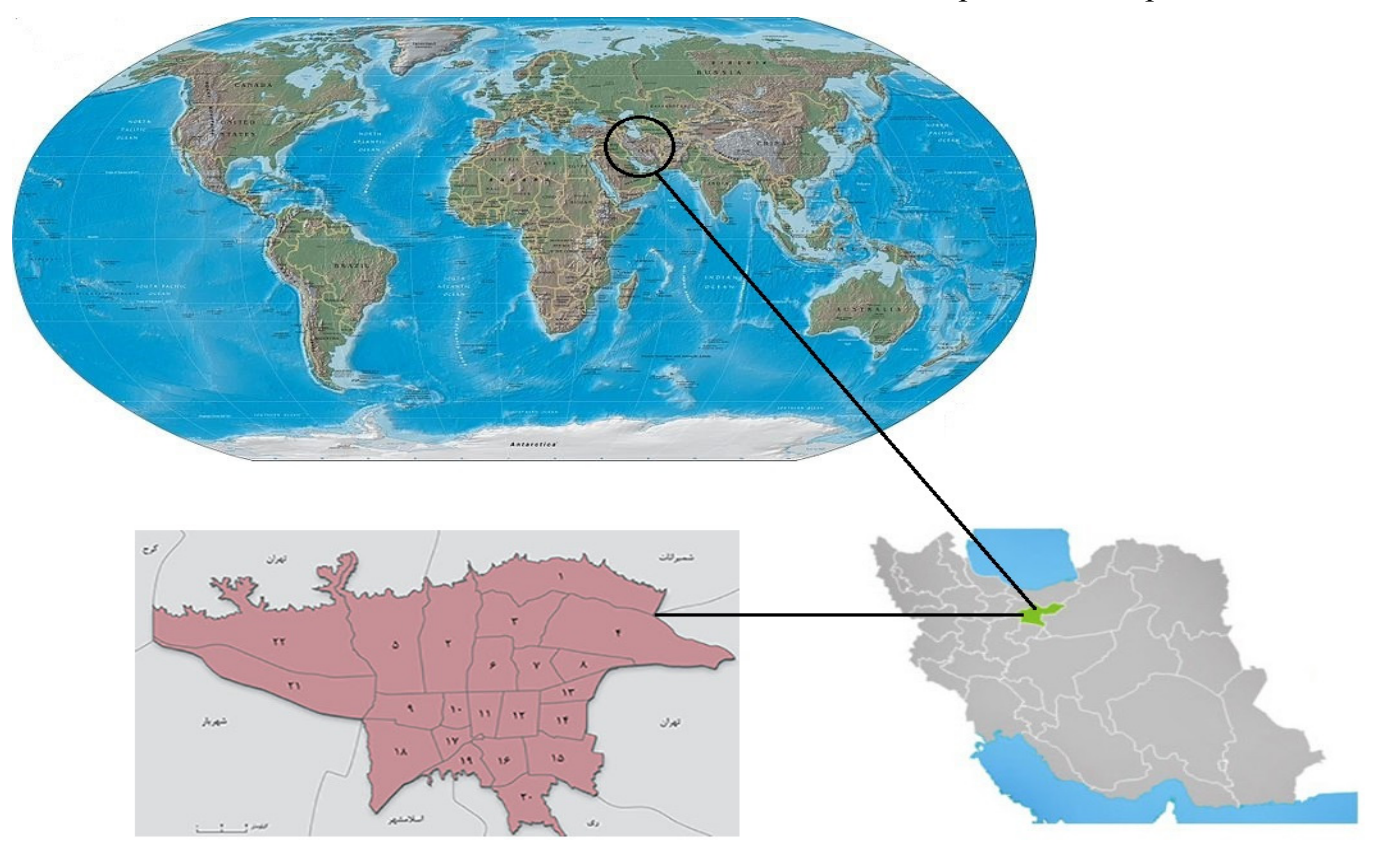

Fig. 1. Map of Iran, Tehran, and its monitoring stations 
tion of the adverse health impacts is linked to the volume of the inhalation of air pollutants. Thus, the input data had to be in weight/volume units $(\mu \mathrm{g} / \mathrm{m} 3)$. Thus, temperature and pressure data were converted into suitable units using Excel. To convert the unit of mass to the unit of volume, the following public formula was applied in which $\mathrm{P}$ represents air pressure, $\mathrm{T}$ temperature, and MW molecular weight of the pollutants:

$$
\frac{\mu g}{m^{3}}=\frac{P(m m H g) \times M W \times p p m}{62.4 \times T\left({ }^{\circ} \mathrm{K}\right)} \times 1000
$$

\section{AirQ software}

We used the software that was proposed by the WHO to assess the health effect of air pollution. AirQ software was designed by WHO European Centre for Environment Health, Belhaven Division. AirQ is a particular software designed to evaluate the effect of exposure to air pollutants on human health. The evaluation is based on the attributable proportion (AP), defined as the fraction of the health consequence in a specified population attributable to exposure to a given air pollutant. Attributable part or attributed ratio is a part of health consequence that is linked to the exposure of a particular population (assuming a possible association between exposures and health outcome without significant confounding impacts on this relationship) during a defined period. This component is ponderable using the following formula $(16,21)$ :

$$
\mathrm{AP}=\mathrm{SUM}\{[\mathrm{RR}(\mathrm{c})-1] \times \mathrm{p}(\mathrm{c})\} / \mathrm{SUM}[\mathrm{RR}(\mathrm{c}) \times \mathrm{p}(\mathrm{c})]
$$

Where $R R(c)$ is the relative risk of health effect in group $c$ or the target group and $\mathrm{P}(\mathrm{c})$ is the ratio of group $\mathrm{c}$ or the target group. The relative risk (RR) of the chosen health effect can be considered using exposure-response functions. By understanding the rate of incidence based on the selected health effect (I) in the target society, the content attributed to population exposure (or the number of cases each population unit) (IE) can be assessed as follows:

$$
\mathrm{IE}=\mathrm{I} \times \mathrm{AP}
$$

In a population with the value of $\mathrm{N}$, this rate can be changed to the number of evaluated cases due to exposure

$$
(\mathrm{NE}): \mathrm{NE}=\mathrm{IE} \times \mathrm{N}
$$

Baseline incidence (BI) multiplied by population value and attributable proportion (AP) is divided by $10^{5}$ to find the number of excess cases (7).

$$
\left(\frac{\text { Baseline incidence } \times \text { Population }}{10^{5}}\right)
$$

\section{Attributable proportion $=$ No. of excess cases} (5)

Baseline incidence (BI) and relative risks with $95 \%$ confidence intervals $(95 \% \mathrm{CI})$ used for the health effect estimation in the present study are presented in Table 2. Relative risks and BI were used in this study based on other studies conducted in Iran $(22,23)$ and were compared with those of the World Bank (24) and World Health Statistics 2013 (25) to ensure the accuracy and precision.

To estimate the health impacts and outcomes by AirQ, WHO default values for baseline incidence and relative risk (with 95\% confidence intervals) can be applied. By implementing the software, these values are shown automatically.

Also, the default values can be exchanged with consulates of baseline incidence and relative risk (95\% confidence intervals) using regional and national epidemiological studies. Because there is a significant difference between Iran and Europe in the age pyramid and because the software's own default data are based on the European societies, it cannot be applied. So, by searching and reviewing relevant studies, we tried to estimate the incidence and relative risks for Iran. Relative risk (RR) with $95 \%$ confidence intervals $(95 \% \mathrm{CI})$ for cardiovascular diseases attributed to $\mathrm{PM}_{10}$ in the upper, central, and lower format was $1 / 013,1 / 009$, and $1 / 006$, respectively, and the estimated baseline incidence was 436 . The respiratory diseases attributed to $\mathrm{PM}_{10}$ in the upper, central, and lower format was $1 / 0112,1 / 008$, and $1 / 0048$, respectively, and the estimated baseline incidence was 1260 . Relative risks for acute myocardial infarction attributed to $\mathrm{SO}_{2}$ in the format of upper, central, and lower was 1/0101, 1/0064, and $1 / 0026$, respectively, and the estimated baseline incidence was 132 .

By locating (RR) consulate confidence intervals in the formula, we could assess the low and high limits of AP consulate and the range of cases due to the anticipated exposure. Finally, by registering the processed data in AirQ software, the results of the attributed part as regards to the number of emergency hospitalization due to air pollution during the recent decade, were calculated by the software.

\section{Results}

After performing the analysis based on the results taken from AirQ software, the excess cases of emergency hospitalizations and attributable proportion to atmospheric air pollutants were evaluated. The findings of the present study showed that emergency admissions due to respiratory and cardiovascular diseases have a significant association with an increase in pollutant levels. Number of hospitalizations in each year is displayed in Table 1. Also, the attributable proportion of health end points of each year is demonstrated in Table 2.

\section{Discussion}

In this study, the number of emergency hospitalizations due to cardiovascular and respiratory diseases and acute myocardial infarction caused by exposure to air pollution in Tehran during the recent decade was quantified and evaluated. The findings of this study revealed that air pollution has raised hospital emergency admissions due to respiratory and cardiovascular diseases in Tehran. Quantifying the impacts of air pollution describes how many people are affected by air pollutants and shows the acute 


\begin{tabular}{|c|c|c|c|}
\hline \multicolumn{4}{|c|}{ Health Endpoint } \\
\hline Year & $\begin{array}{l}\text { Hospital admissions due to } \\
\text { cardiovascular diseases }\end{array}$ & $\begin{array}{c}\text { Hospital admissions due to respiratory } \\
\text { diseases } \\
\text { Number of hospitalizations }\end{array}$ & Acute myocardial infarction \\
\hline 2005 & 1797(1219-2539) & $4643(2838-6385)$ & $228(94-356)$ \\
\hline 2006 & $1280(863-1820)$ & $3301(2006-4564)$ & $476(198-733)$ \\
\hline 2007 & $1766(1196-2497)$ & $4650(2784-6277)$ & $548(229-840)$ \\
\hline 2008 & $1980(1344-2794)$ & $5117(3130-7031)$ & $221(91-345)$ \\
\hline 2009 & $2132(1448-3004)$ & $5511(3375-7563)$ & $516(215-794)$ \\
\hline 2010 & $2703(1845-3786)$ & $6999(4308-9558)$ & $268(110-418)$ \\
\hline 2011 & $2389(1626-3360)$ & $6180(3791-8466)$ & $362(149-561)$ \\
\hline 2012 & $2494(1698-3504)$ & $6452(3960-8833)$ & $311(128-484)$ \\
\hline 2013 & $2158(1465-3044)$ & $5577(3412-7660)$ & $232(95-362)$ \\
\hline 2014 & $2291(1556-3228)$ & $5922(3626-8127)$ & $225(92-352)$ \\
\hline 2005-2014 & $20990(14260-29576)$ & $54352(33230-74464)$ & $3478(1401-5245)$ \\
\hline \multicolumn{4}{|c|}{ Health endpoint } \\
\hline Year & $\begin{array}{l}\text { Hospital admissions due to } \\
\text { cardiovascular diseases }\end{array}$ & $\begin{array}{c}\text { Hospital admissions due to respiratory } \\
\text { diseases } \\
\text { Attributable proportion }\end{array}$ & Acute myocardial infarction \\
\hline 2005 & $5.09(3.45-7.19)$ & $4.55(2.78-6.25)$ & $2.13(0.78-3.33)$ \\
\hline 2006 & $3.53(2.38-5.02)$ & $3.15(1.91-4.35)$ & $4.34(1.81-6.68)$ \\
\hline 2007 & $4.8(3.25-6.79)$ & $4.29(2.62-5.9)$ & $4.92(2.06-7.55)$ \\
\hline 2008 & $5.31(3.6-7.49)$ & $4.74(2.9-6.52)$ & $1.96(0.8-3.06)$ \\
\hline 2009 & $5.63(3.82-7.94)$ & $5.04(3.08-6.91)$ & $4.49(1.87-6.91)$ \\
\hline 2010 & $7.04(4.81-8.86)$ & $6.31(3.88-8.61)$ & $2.31(0.95-3.6)$ \\
\hline 2011 & $6.13(4.17-8.63)$ & $5.49(3.37-7.52)$ & $3.07(1.27-4.76)$ \\
\hline 2012 & $6.31(4.30-8.87)$ & $5.65(3.47-7.74)$ & $2.6(1.07-4.05)$ \\
\hline 2013 & $5.38(3.65-7.6)$ & $4.81(2.94-6.61)$ & $1.91(0.78-2.98)$ \\
\hline 2014 & $5.63(3.83-7.94)$ & $5.04(3.08-6.92)$ & $1.83(0.75-2.86)$ \\
\hline
\end{tabular}

status of air quality. Making a right connection between exposure to various concentrations of air pollutants and their effects on the health of people is very difficult. This approach is one of the most valid methods presented by the WHO and is applied to investigate the health impact of air pollutants.

According to Tables 1 and 2, the number of hospitalizations due to cardiovascular and respiratory diseases attributed to the particulate matter was 20990 and 54352 persons, respectively, during 2005-2014, demonstrating that the particulate matter caused more hospital emergency admissions compared to other factors. The studies performed by Kosha et al. have also proved that there is a main link between the concentration of the particulate matter and hospital admissions of cardiovascular and respiratory patients in Tabriz. They showed that by the rise in the concentration of the particulate matter, the number of admissions of patients suffering from the abovementioned diseases to hospitals has increased (26).

The study conducted by Ebrahimzadeh et al. also demonstrated that by every $110 \mu \mathrm{g}$ raise of air pollutants in a cubic meter of air, there will be an increase of $1.35 \%$ and $0.021 \%$, respectively, in the incidence of cardiac and respiratory diseases in Sanandaj (27). Investigations performed by Pan et al. displayed a considerable relationship between storms of dust and the particulate matter with the increase in hospital emergency admissions (28). According to Table 1 , the number of hospital emergency visits due to acute myocardial infarction resulting from exposure to sulfur dioxide during the past decade was 3478. Also, studies conducted in Tehran proved that particulate matter, sulfur dioxide, and nitrogen dioxide are the most significant causes of mortality resulting from cardiovascular diseases in Tehran (29). The high level of sulfur dioxide is caused by the failure to eliminate sulfur from fuel, particularly diesel fuel. In another study in Australia, the most significant reason for admission of patients to hospitals' emergency departments in the city of Brisbane was respiratory complications; in addition, $\mathrm{PM}_{10}$ and ozone air levels were pollutant factors (30). Zhong also demonstrated that the main reason for children's visit to hospitals was asthma attack due to exposure to the particulate matter and ozone (31). In a research conducted by Ghanbari et al. in Tabriz, a direct connection was found between exposure to gaseous pollutants and respiratory diseases and chronic obstructive pulmonary disease in Tabriz; they observed that 69 patients were hospitalized because of respiratory diseases during only one year and 32 cases suffered from chronic obstructive pulmonary disease (32). Based on the results of our study, the main air pollutant in Tehran is the particulate matter. In summary, the study findings have shown a significant positive link between the respiratory and cardiovascular patients visits to hospitals and air pollution in Tehran. With equipping the hospitals and health centers and providing specialized education, the harmful health impacts can be reduced during air pollution. According to the Health and Air Pollution (PAPA) study in Asia, although the social and environmental conditions may be entirely different, it is helpful to apply estimates of health impacts of air pollution studies in the West in Asian studies (33). Thus, to calculate the health impacts of air pollution in Tehran, AirQ software was applied in this study. Our results were mainly consistent with studies performed in European countries and the United States. In another study, the particulate matter seemed to be the main pollutant, which is often represented as having a 


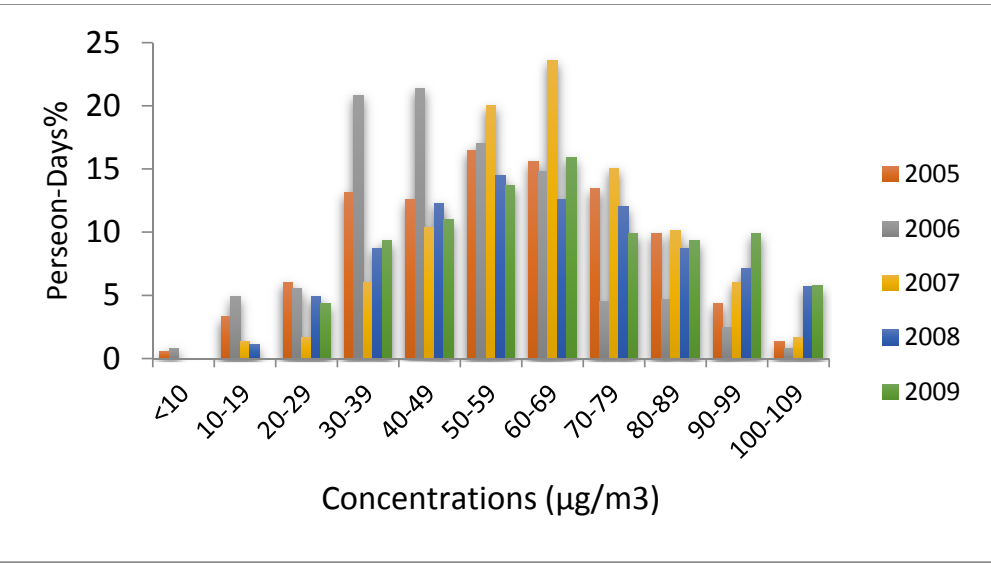

Fig. 2. (a) The percentage of days that residents in Tehran were exposed to various concentrations of $\mathrm{PM}_{10}$ during $2005-2009$

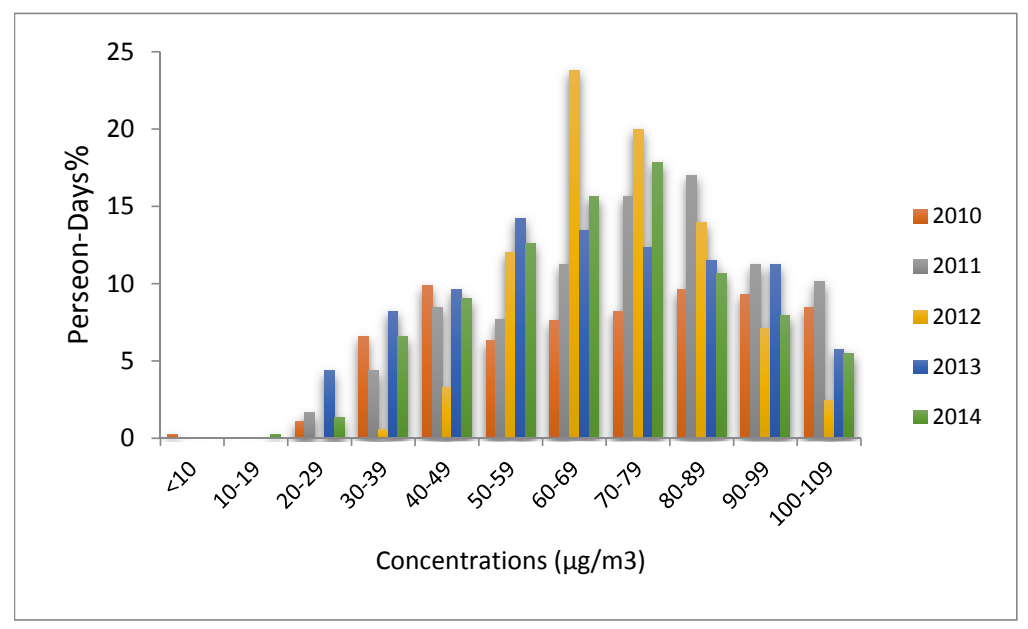

Fig. 2. (b) The percentage of days that residents in Tehran were exposed to various concentrations of $\mathrm{PM}_{10}$ during $2010-2014$

possible causal impact on cardiovascular disease (CVD) cases. We found considerable associations between the particulate matter and CVD. The observed impacts of $\mathrm{SO}_{2}$ were commonly not retained in the attendance of other pollutants, and where they were, the main impacts were in reverse paths. This might be due to the linearity between $\mathrm{SO}_{2}$ levels and other pollutant concentrations, which is common in this type of studies. This study had some limitations. The health impacts were only centralized on individual compositions and (RR) evaluations were taken from studies on other populations.

\section{Conclusion}

This study demonstrated that air pollution in Tehran has increased patients' admissions to emergency departments due to respiratory and cardiovascular diseases. Thus, the policy-makers, managers, and specialists should focus on and try to reduce air pollution. Furthermore, hospitals, especially the emergency, cardiovascular, and respiratory wards, should be prepared to receive more patients in days where air pollution is more than the standard level. We recommend conducting further studies on this topic. The results of this study were consistent with those of other studies, and despite the limitations, which were typical of similar studies, it was shown that this method is practical and easy and also beneficial in decision-making.

\section{Acknowledgement}

This work was funded by Iran University of Medical Sciences (Grant number: 25455). We also thank the Environmental Protection Agency of Tehran and Air Quality Control Company for providing us with the data of pollutants' concentrations. We acknowledge the critical comments from anonymous reviewers and editors.

\section{Conflict of Interests}

The authors declare that they have no competing interests.

\section{References}

1. Marzouni MB, Alizadeh T, Banafsheh MR, Khorshiddoust AM, Ghozikali MG, Akbaripoor S, et al. A comparison of health impacts assessment for PM10 during two successive years in the ambient air of Kermanshah, Iran. Atmos Pollut Res. 2016;7(5):768-74.

2. WHO. Burden of disease from Ambient and household Air Pollution. 2014.

3. Kermani M, Dowlati M, Jonidi Ja fari A, Rezaei Kalantari R, Sadat Sakhaei F. Effect of Air Pollution on the Emergency Admissions of 
Cardiovascular and Respiratory Patients, Using the Air Quality Model: A Study in Tehran, 2005-2014. HEDQ. 2016;1(3):137-46.

4. Bahrami Asl F, Kermani M, Aghaei M, Karimzadeh S, Salahshour Arian S, Shahsavani A, et al. Estimation of Diseases and Mortality Attributed to NO2 pollutant in five metropolises of Iran using AirQ model in 2011-2012. J Mazandaran Uni Med Sci. 2015;24(121):23949.

5. Kermani M, Aghaei M, Gholami M, Bahrami asl F, Karimzade SA, Falah S, et al. Estimation of Mortality Attributed to PM2.5 and CO Exposure in eight industrialized cities of Iran during 2011. Iran Occupat Health J. 2016;13(4):49-61.

6. Kermani M, Fallah Jokandan S, Aghaei M, Bahrami Asl F, Karimzadeh S, Dowlati M. Estimation of the Number of Excess Hospitalizations Attributed to Sulfur Dioxide in Six Major Cities of Iran. Health Scope. 2016;5(4):e38736.

7. Motesaddi Zarandi S, Raei Shaktaie H, Yazdani Cheratee J, Hosseinzade F, Dowlati M. Evaluation of PM2.5 Concentration and Determinant Parameters on its Distribution in Tehran's Metro System in 2012. J Mazandaran Uni Med Sci. 2013;22(2):36-46.

8. Loomis D, Grosse Y, Lauby-Secretan B, El Ghissassi F, Bouvard V, Benbrahim-Tallaa L, et al. The carcinogenicity of outdoor air pollution. Lancet Oncol. 2013;14(13):1262-3.

9. Fattore E, Paiano V, Borgini A, Tittarelli A, Bertoldi M, Crosignani $\mathrm{P}$, et al. Human health risk in relation to air quality in two municipalities in an industrialized area of Northern Italy. Environ Res. 2011;111(8):1321-7.

10.Sang Jin J. The Impact of Air Pollution on Human Health in Suwon City. AJAE. 2013;7(4):227-33

11. Kermani, M., Dowlati, M., Jonidi Jafari, A., \& Rezaei Kalantari, R. Number of mortality, chronic obstructive pulmonary disease and acute myocardial infarction due to exposure to sulfur dioxide in Tehran, during 2005-2014. Koomesh J.2018;20(1), 34-42

12.Kermani M, Aghaei M, Bahramiasl F, Gholami M, Fallah Jokandan S, Dolati M, et al. Estimation of cardiovascular death, myocardial infarction and chronic obstructive pulmonary disease (COPD) attributed to $\mathrm{SO} 2$ exposure in six industrialized metropolises of Iran. Razi J Med Sci. 2016;23(145):12-21.

13. Kermani M., Dowlati M, Jafari AJ, Kalantari RR. Health risks attributed to particulate matter of 2.5 microns or less in Tehran air 2005-2014. J Kermanshah Uni Med Sci. 2016;20(3), 99-105

14. Kermani M, Dowlati M, Jonidi Jafari A, Rezaei Kalantari R. Health impact caused by exposure to particulate matter in the air of Tehran in the past decade. Tehran Uni Med J. 2017;74(12):885-892.

15. Puett RC, Hart JE, Suh H, Mittleman M, Laden F. Particulate matter exposures, mortality, and cardiovascular disease in the health professionals follow-up study. Environ. Health Perspect. 2011;119(8): 1130-5.

16. Oliveri Conti G, Heibati B, Kloog I, Fiore M, Ferrante M. A review of AirQ Models and their applications for forecasting the air pollution health outcomes. Environ Sci Pollut Res. 2017:1-20.

17. Lippmann $\mathrm{M}$, Ito $\mathrm{K}$, Nadas A, Burnett $\mathrm{R}$. ssociation of particulatematter components with dailymortality and morbidity in urban populations. Res Rep Health Eff Ins. 2000;95(5):72.

18. Kermani M, Dowlati M, Jonidi Jafari A, Rezaei Kalantari R. Estimation of Mortality, Acute Myocardial Infarction and Chronic Obstructive Pulmonary Disease due to Exposure to O3, NO2, and SO2 in Ambient Air in Tehran. J Mazandaran Uni Med Sci. 2016;26(138):96-107.

19. Raaee Shaktaie H, Motesaddi Zarandi S, Zazouli M, Yazdani Cheratee J, Hosseinzade F, Dowlati M. Study Concentration of particulate matter with aerodynamic diameter less than 10 micron (PM10) in the metro underground transport system of Tehran. J Mazandaran Uni Med Sci. 2017;27(151):166-179.

20.Younusian M. Air pollution epidemiology, studies and the ahead challenges Science and Health Journal. Iranian Epidemiology Congress Sixth. 2010. p. 34-5.

21. WHO. Quantification of the Health Effects of Exposure to Air Pollution. Bilthoven, Netherlands. 2000

22. Gholampour A, Nabizadeh R, Naseri S, Yunesian M, Taghipour H, Rastkari N, et al. Exposure and health impacts of outdoor particulate matter in two urban and industrialized area of Tabriz, Iran. J Environ Health Sci Eng. 2014;12:27.

23. Naddafi K, Hassanvand MS, Yunesian M, Momeniha F, Nabizadeh $\mathrm{R}$, Faridi $\mathrm{S}$, et al. Health impact assessment of air pollution in megacity of Tehran, Iran. Iranian J Environ Health Sci Eng.
2012;10(1):28

24. World Bank. World Bank Database. World Bank. http://data.worldbank.org/ indicator. 2012.

25. WHO. World health statistics 2013. Switzerland: WHO Library Cataloguing-in-Publication Data; 2013.

26. Kosha A, Rajabi A. The relationship between the concentration of suspended particles in the air and the rate of emergency admissions to hospital in Tabriz (Persian). Fourteenth International Conference on Environmental Health; Yazd. 2010.

27. Ebrahimzadeh L, Ebrahimi S, Habibi S. Effects of Dust Storm on Emergency Admission for heart and respiratory diseases in Sanandaj (Persian). Fourteenth International Conference on Environmental Health; Yazd. 2010.

28. Pan X, Junhan C. Study on health effects of dust stroms in China, Seol, Korea. J Environ Health. 2010;408(4):26-8.

29. Mohamadi $\mathrm{H}$. The correlation of Tehran atmospheric parameters and air pollution with the heart attack mortality rate (1999-2003 study periods). J Geogr Res. 2006;58(38):47-66.

30. Chen L, Mengerson K, Tong S. Spatiotemporal relationship between particle air pollution and respiratory emergency hospital admission in Brisbane, Australia. Sci. Total Environ. 2007;373(1):57-67.

31. Zhong W, Levin L, Reponen T, Hershey GK, Adhikari A, Shukla R, et al. Analysis of short-term influences of ambient aeroallergens on pediatric asthma hospital visits. Sci. Total Environ. 2006;370(23):330-6.

32. Ghanbari Ghozikali M, Heibati B, Naddafi K, Kloog I, Oliveri Conti G, Polosa R, et al. Evaluation of Chronic Obstructive Pulmonary Disease (COPD) attributed to atmospheric O3, NO2, and $\mathrm{SO} 2$ using Air Q Model (2011-2012 year). Environ Res. 2016;144(Pt A):99-105. 33. Wong CM, Vichit-Vadakan N, Kan H, Qian Z. Public Health and Air Pollution in Asia (PAPA): a multicity study of short-term effects of air pollution on mortality. Environ. Health Perspect. 2008;116(9): 1195-202. 